\title{
Time-Dependent Changes in Local and Serum Levels of Inflammatory Cytokines as Markers for Incised Wound Aging of Skeletal Muscles
}

\author{
Mohammed Hassan Gaballah, ${ }^{1,2, *}$ Tetsuya Horita, ${ }^{1, *}$ Masataka Takamiya, ${ }^{3}$ \\ Keisuke Yokoji, ${ }^{1}$ Mamiko Fukuta, ${ }^{1}$ Hideaki Kato ${ }^{1}$ and Yasuhiro Aoki ${ }^{1}$ \\ ${ }^{1}$ Department of Forensic Medicine, Nagoya City University Graduate School of Medical Sciences, Nagoya, Aichi, \\ Japan \\ ${ }^{2}$ Egyptian Forensic Medicine Authority, Ministry of Justice, Cairo, Egypt \\ ${ }^{3}$ Department of Forensic Medicine, Iwate Medical University, Siwa-gun, Iwate, Japan
}

\begin{abstract}
Wound age estimation is an important research field in forensic pathology. The expression levels of cytokines in the incised skeletal muscle were analyzed using a mouse model to explore the applicability for wound aging. A 5-mm long incisional wound was made at the biceps femoris muscle, and the muscle and serum were sampled at $6,12,24$ and 48 hours after injury. Using a multiplex bead-based immunoassay, we measured the tissue levels of nine cytokines (IL-1 $\beta$, IL-6, IL-7, CCL2, CCL3, CCL4, CXCL1, CXCL2, and $C X C L 10$ ), which are all involved in the pathways of inflammatory response and tissue injury. Immunoassay of post-injury muscle samples revealed significant increases in the levels of six cytokines, except for CCL3, CCL4 and IL-7, at 6 hours after injury. The elevated tissue levels of these six cytokines were maintained during 48 hours after injury, although the levels of IL- 6 and CXCL1 were significantly decreased at 12 hours. In case of CCL3, its tissue levels were increased only at 12 hours. By contrast, CCL4 and IL-7 levels were increased only at 48 hours. Moreover, serum levels of most cytokines, except for CXCL1, remained unchanged during 24 hours after injury, followed by significant increases at 48 hours. Serum CXCL1 levels were increased at 6 hours and then decreased to the basal levels. Thus, the significant increase in the muscle levels of CXCL1 and IL-7 was observed at 6 and 48 hours after injury, respectively. Measuring muscle CXCL1 and IL-7 levels is helpful for estimating incised wound aging.
\end{abstract}

Keywords: bead-based immunoassay; cytokines; sharp force injury; skeletal muscle; wound aging

Tohoku J. Exp. Med., 2018 May, 245 (1), 29-35. C 2018 Tohoku University Medical Press

\section{Introduction}

Wound age estimation is one of the most important research fields in forensic pathology and a number of research projects and the majority of scientific studies have dealt with the timing of dermal injuries (Grellner and Madea 2007). On the other hand, sharp force injuries in skeletal muscles have received little attention, although skeletal muscles are, like skin, distributed throughout the whole body, and often affected in cases of fatal and serious injuries such as stab and incised wounds, which are of importance in the forensic field (Gaballah et al. 2016). Moreover, multiplex bead-based protein immunoassay was used in some studies of wound age estimation in human dermal wounds (Takamiya et al. 2007, 2009), but no studies have yet been conducted on incised wounds in skeletal muscles. Although comprehensive investigation of the che- modynamics of muscle injury has not been reported, recent histopathological and molecular biological studies on skeletal muscle contusion suggested the potential of some cytokines as markers for wound age determination ( $\mathrm{Yu}$ et al. 2016; Tian et al. 2016). Because skin and muscle are usually affected simultaneously and each injury would induce, at least partially, a different cytokine cascade (Gaballah et al. 2016), information on both would be useful for more integrated or refined wound age estimation.

In a previous study, the authors performed a DNA microarray analysis on the injured skeletal muscle samples and validated the results with real time quantitative reverse transcription PCR (RT-qRT-PCR) of some significantly upregulated genes involved in inflammatory response pathways: interleukin-1 $\beta$ (IL-1 $\beta$ ), interleukin-6 (IL-6), IL-7, chemokine (C-C motif) ligand 4 (CCL4), and chemokine (C-X-C motif) ligand 5 (Gaballah et al. 2016). The results

Received October 30, 2017; revised and accepted April 23, 2018. Published online May 12, 2018; doi: 10.1620/tjem.245.29.

*These authors contributed equally to this work.

Correspondence: Yasuhiro Aoki, M.D., Ph.D., Department of Forensic Medicine, Nagoya City University Graduate School of Medical Sciences, 1 Kawasumi, Mizuho-cho, Mizuho-ku, Nagoya, Aichi 467-8601, Japan.

e-mail: aokiy@med.nagoya-cu.ac.jp 
of the DNA microarray analysis also demonstrated that a large number of expressed genes were possible markers to explore the biological effect of incised injuries. However, because not all mRNAs are identical regarding translation into proteins (Schwanhäusser et al. 2011), quantitative analysis of protein expression should be mandatory for understanding the biological response to skeletal muscle injury and repair. Furthermore, the utility of protein markers may be superior to that of nucleotides in forensic practice, due to the possible susceptibility of the mRNA to postmortem changes (Madea and Saukko 2010; Maeda et al. 2010).

In the present study, using multiplex bead-based immunoassay, we measured the tissue levels of nine selected cytokines, IL-1 $\beta$, IL-6, IL-7, chemokine (C-C motif) ligand 2 (CCL2), chemokine (C-C motif) ligand 3 (CCL3), CCL4, chemokine (C-X-C motif) ligand 1 (CXCL1), chemokine (C-X-C motif) ligand 2 (CXCL2), and chemokine (C-X-C motif) ligand 10 (CXCL10) in the mouse muscle with an incisional wound. These cytokines were selected based on the results of DNA microarray analysis (Gaballah et al. 2016). In addition to the injured muscle samples, serum levels of each cytokine were also measured chronologically to access the systemic effect of inflammatory response. We also measured the mRNA levels of five chemokine (CCL2, CCL3, CXCL1, CXCL2, and CXCL10) by RT-qRT-PCR, because they were not examined in the previous study (Gaballah et al. 2016).

\section{Materials and Methods}

\section{Animal treatment}

Muscle samples were obtained and processed as described in a previous report (Gaballah et al. 2016). Briefly, pathogen-free 8-weekold male BALB/c mice were divided into five groups (control, 6,12 , 24 and 48 hours post-injury groups: $n=18$ for each group). An incisional wound in the skin on the dorsal aspect of the left hind limb was created using a sterilized straight stainless scissor, and then a 5-mm long incisional wound was made at the biceps femoris muscle of the anesthetized mice. Subsequently the skin incision was closed using silk suture. At the specific designated time after injury, the wounded muscle tissue sample, $3 \mathrm{~mm}$ in thickness, with the site of incision in the center, was excised and control specimens of the biceps femoris muscle from euthanized non-injured mice were collected. All experiments were performed in compliance with the relevant Japanese and institutional laws and guidelines and approved by the Nagoya City University (NCU) animal ethics committee (authorization number H26-M02).

\section{Multiplex bead-based immunoassay}

The tissue lysis step using a lysis buffer (Tissue Extraction Reagent I, Invitrogen, USA) was performed according to the manufacturer's instructions. The muscle tissue samples ( $30 \mathrm{mg}$ each, $\mathrm{n}=8$ for each group) were immediately homogenized in a $1.5 \mathrm{~mL}$ sterilized plastic tube on ice for 10 minutes using a motor-driven pellet pestle mixer (Fisher Scientific, USA) in the lysis buffer cocktail composed of $500 \mu \mathrm{L}$ of Tissue Extraction Reagent I and $50 \mu \mathrm{L}$ of protease inhibitor solution (SIGMA, USA). Tissue lysates were centrifuged at $10,000 \mathrm{~g}$ for $10 \mathrm{~min}$ at $4^{\circ} \mathrm{C}$. The supernatant was then transferred to a new tube and stored at $<-70^{\circ} \mathrm{C}$. Approximately $1.5 \mathrm{~mL}$ of whole blood was also obtained from the heart using a $24 \mathrm{G}$ syringe needle directly after euthanizing each animal. The blood samples were allowed to clot for 2 hours at room temperature. The samples were then centrifuged at $1,000 \mathrm{~g}$ for $10 \mathrm{~min}$ at $4^{\circ} \mathrm{C}$, and serum was collected and stored at $<-70^{\circ} \mathrm{C}$.

Levels of cytokines in supernatants derived from muscle sample homogenates and serum samples at different time points were measured using a MILLIPLEX ${ }^{\circledR}$ MAP Kit (MCYTOMAG-70K-9 plex, Merck Millipore, Germany). Assays were run according to the manufacturer's instructions. The samples were diluted with the diluent buffer provided with the kit. Absorbance was measured with the MAGPIX ${ }^{\circledR}$ System (Merck Millipore), and the results expressed as $\mathrm{pg} / \mathrm{mL}$ (quantitative lower detection limit: 3.4-611 pg/mL depending on each analyte) were analyzed using MILLIPLEX ${ }^{\mathbb{B}}$ Analyst 5.1. The nine cytokines measured were IL-1 $\beta$, IL-6, IL-7, CXCL10 (also known as interferon $\gamma$-induced protein 10: IP-10), CXCL1 (keratinocyte-derived chemokine: KC), CCL2 (monocyte chemotactic protein 1: MCP-1), CCL3 (macrophage inflammatory protein $1 \alpha$ : MIP-1 $\alpha$ ), CCL4 (macrophage inflammatory protein $1 \beta$ : MIP-1 $\beta$ ), and CXCL2 (macrophage inflammatory protein 2: MIP-2). These cytokines were selected based on the results of DNA microarray analysis (Gaballah et al. 2016). All samples were analyzed in duplicate and mean values were employed. Statistical analysis of cytokine expressions between controls and each injured tissue sample was performed using the Shapiro-Wilk test and Steel-Dwass test. For all statistical analyses, $P<0.05$ was considered statistically significant.

\section{$R T-q R T-P C R$}

The mRNA levels of five chemokines (mus musculus CCL2, CCL3, CXCL1, CXCL2, and CXCL10) were measured by RT-qRTPCR. Extraction of mRNA and reverse transcription were conducted on 10 mouse muscle samples at each time point (total $\mathrm{n}=50$ ) as described in the previous report (Gaballah et al. 2016). TaqMan ${ }^{\circledR}$ Gene Expression Assays were performed with the following customdesigned primer set for each cDNA sequence (Applied Biosystems, USA): CCL2: Mm00441242 m, NM 011333.3, 74 bp; CCL3: Mm00441259 g1, NM 011337.2, 65 bp; and CXCL1: Mm04207460 m1, NM 008176.3, 111 bp; CXCL2: Mm00436450 m1, NM 009140.2, 67 bp; CXCL10: Mm00445235 m1, NM 021274.2, 59 bp. For glyceraldehyde 3-phosphate dehydrogenase (GAPDH) used as an internal standard, primers and probe were also supplied with TaqMan ${ }^{\circledR}$ Gene Expression Assays (Mm0099999915 g1). RT-qRTPCR was conducted following protocols discussed in the previous study (Gaballah et al. 2016). Statistical analysis for the comparison of the cytokine mRNA level at different time points was performed as described above.

\section{Results}

Multiplex bead-based immunoassay

Results of examination of the muscle samples showed significant increases in the tissue levels of the six cytokines at 6 hours after injury, namely IL-1 $\beta$, IL-6, CCL2, CXCL1, CXCL2, and CXCL10 (Fig. 1a, b, d, g-i). The elevated tissue levels of these six cytokines were maintained during 48 hours after injury, although the levels of IL- 6 and CXCL1 were significantly decreased at 12 hours after injury. The three remaining cytokines, IL-7, CCL3, and CCL4, showed 


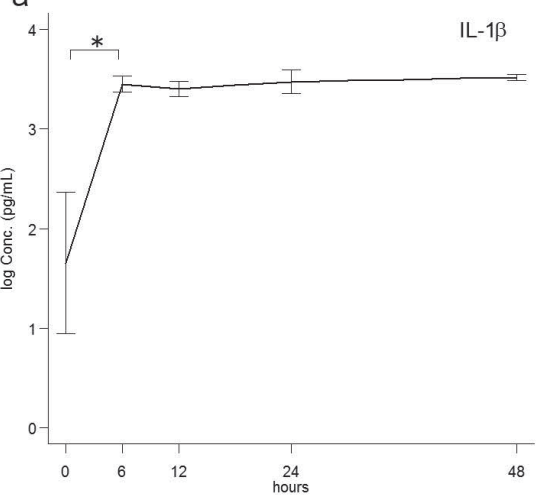

d

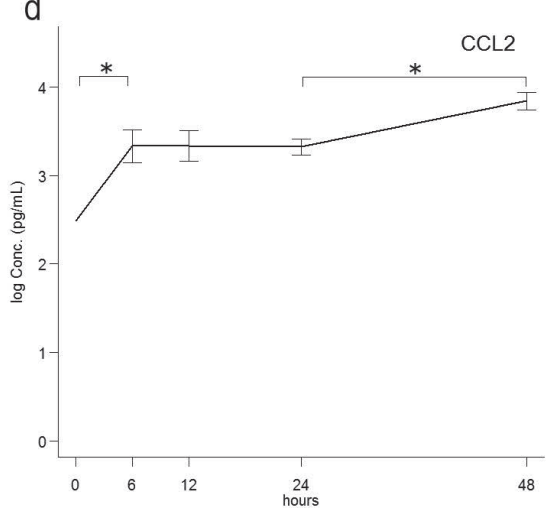

g

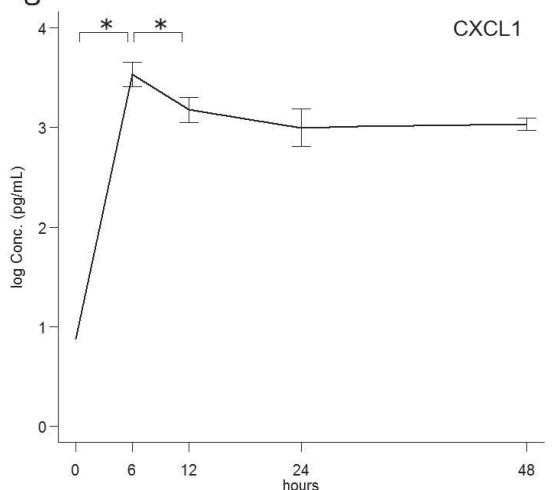

b

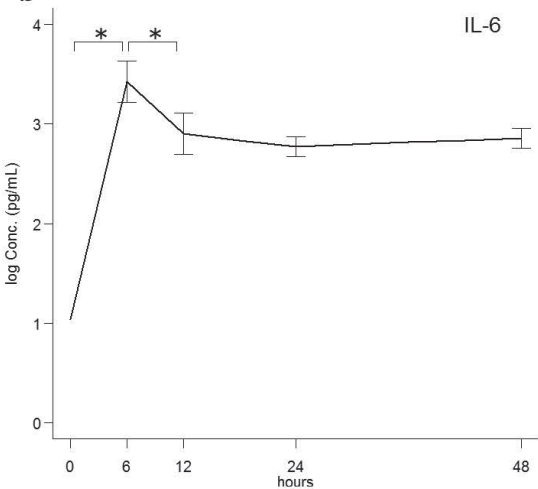

e

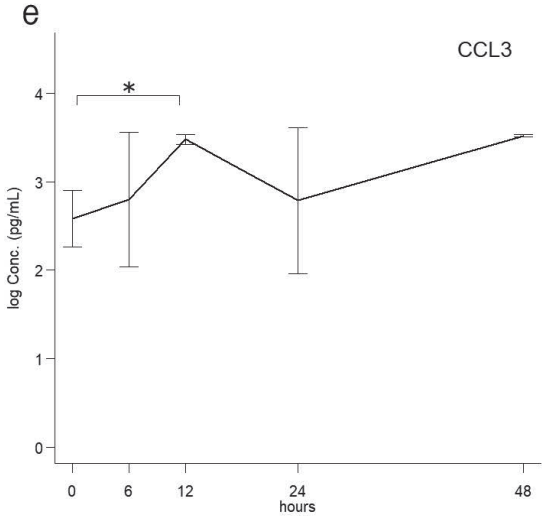

h

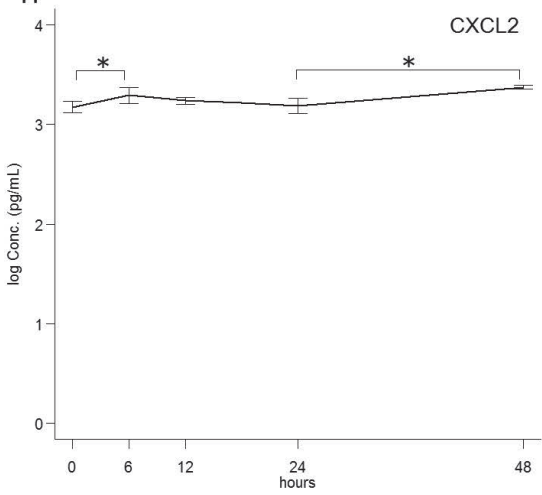

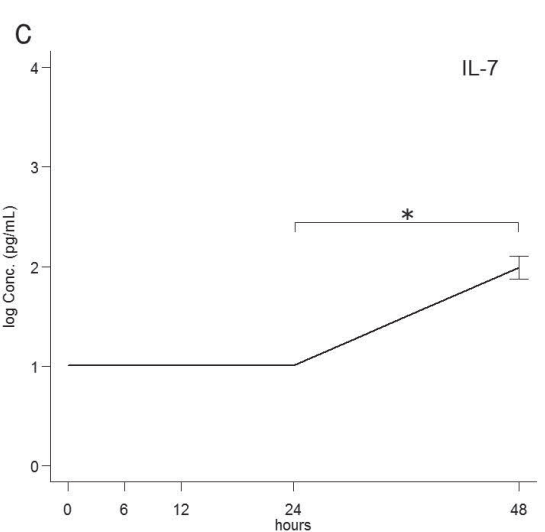

f

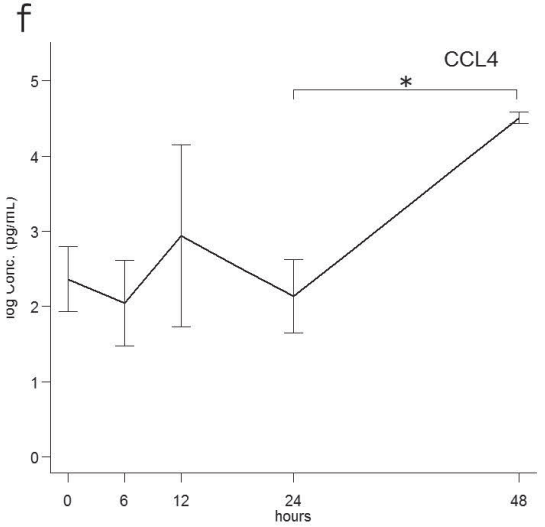

i

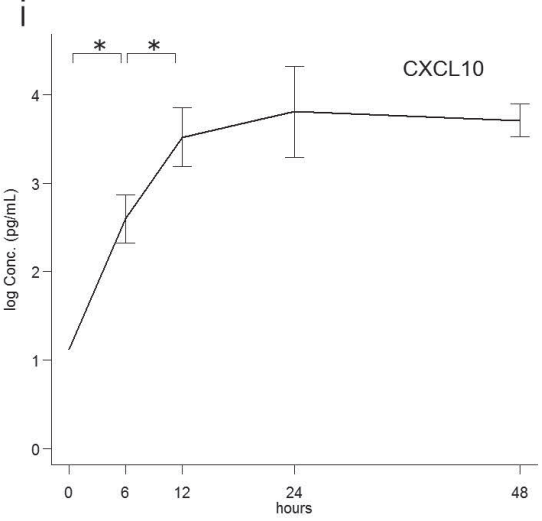

Fig. 1. Semi-log graphs of protein levels of the cytokines in injured muscle.

a: IL- $1 \beta$ levels significantly increased at 6 hours after injury and then remained constant throughout the period observed. b: IL- 6 levels increased rapidly, followed by a significant decrease from 6 to 12 hours after injury. c: IL-7 levels remained below the detection level $(20.4 \mathrm{pg} / \mathrm{mL})$ until 24 hours followed by an increase at 48 hours after injury. d: Concentration of CCL2 protein increased promptly at 6 hours after injury, and another augmentation of expression was observed at 48 hours after injury. e: An increase of CCL3 concentration became obvious at 12 hours after injury, and then fluctuated. f: CCL4 levels increased significantly from 24 to 48 hours. g: CXCL1 levels increased promptly followed by a significant decrease from 6 to 12 hours after injury. h: Concentration of CXCL2 protein increased at 6 hours after injury, and another enhancement of expression was seen at 48 hours after injury. i: An increase of CXCL10 level persisted until 12 hours after injury, and then became relatively constant. Lack of an error bar at the time points implies that the concentration was below the detection limit $(21.6 \mathrm{pg} / \mathrm{mL}$ for IL-6, $611.0 \mathrm{pg} / \mathrm{mL}$ for CCL2, and $26.6 \mathrm{pg} / \mathrm{mL}$ for CXCL10, respectively) and the values plotted on the graphs indicate the half value of the detection limit. $* P<0.05$.

the unique time-dependent changes. The levels of IL-7 and CCL4 were significantly increased only at 48 hours after injury (Fig. 1c, f). In particular, the levels of IL-7 remained below the detection limit during 24 hours after injury. The increase of CCL3 levels became obvious only at 12 hours after injury (Fig. 1e). The significant increase at 48 hours after injury was also observed in CCL2 and CXCL2 levels (Fig. 1d, h). Values of the logarithmic mean concentration of each cytokine at each time point are listed in Table 1.

The examination of the serum samples revealed that 
Table 1. Mean concentration of each cytokine in muscle tissue at each time point $(\mathrm{pg} / \mathrm{mL}, \mathrm{n}=8$ for each group).

\begin{tabular}{lrrrrr}
\hline & \multicolumn{1}{c}{$0 \mathrm{~h}$} & \multicolumn{1}{c}{$6 \mathrm{~h}$} & \multicolumn{1}{c}{$12 \mathrm{~h}$} & \multicolumn{1}{c}{$24 \mathrm{~h}$} & \multicolumn{1}{c}{$48 \mathrm{~h}$} \\
\hline IL-1 $\beta$ & 44.9 & $2,801.8$ & $2,503.2$ & $2,961.7$ & $3,274.3$ \\
IL-6 & $<21.6$ & $2,640.9$ & 792.5 & 591.8 & 716.6 \\
IL-7 & $<20.4$ & $<20.4$ & $<20.4$ & $<20.4$ & 97.3 \\
CCL2 & $<611.0$ & $2,149.2$ & $2,157.2$ & $2,101.7$ & $6,931.1$ \\
CCL3 & 381.3 & 627.0 & $2,990.2$ & 612 & $3,276.3$ \\
CCL4 & 230.0 & 110.4 & 867.9 & 135.9 & $32,146.8$ \\
CXCL1 & 15.0 & $3,412.2$ & $1,500.4$ & 990.9 & $1,079.2$ \\
CXCL2 & $1,487.7$ & $1,950.1$ & $1,726.0$ & $1,540.7$ & $2,354.4$ \\
CXCL10 & $<26.6$ & 393.7 & $3,285.1$ & $6,403.9$ & $5,081.9$ \\
\hline
\end{tabular}

Values with less-than sign $(<)$ indicate below the detection concentration.

CXCL1 was the only cytokine that showed an increase in serum levels at 6 hours and then showed a decrease to the basal levels at 12 hours after injury (Fig. 2g). Importantly, serum levels of IL-6 remained unchanged during 48 hours after injury (Fig. 2b). The serum levels of the seven other cytokines showed only late increases from 24 to 48 hours after injury (Fig. 2a, c-f, h, i). Serum levels of the logarithmic mean concentration of each cytokine at each time point are listed in Table 2.

\section{$R T-q R T-P C R$ analysis}

We also analyzed the time-dependent changes in the expression levels of CCL2, CCL3, CXCL1, CXCL2, and CXCL10 mRNAs, because they were not analyzed in our previous study (Gaballah et al. 2016). The RT-qRT-PCR results are summarized in Table 3, together with the reported expression profiles of IL-1 $\beta$, IL-6, IL-7, and CCL4 mRNAs (Gaballah et al. 2016). Overall, the expression levels of all listed cytokine mRNAs were significantly increased in muscles at 6 hours after injury and were maintained at the elevated levels during 48 hours, except for the expression levels of IL-7 mRNA, with the significant increase at 12 hours (Gaballah et al. 2016). The detailed expression profiles of cytokine mRNAs are summarized in Table 3.

We also measured the cytokine levels in the biceps femoris muscle of contralateral side (the right side) of the injured mice, because obtaining a parallel control is unrealistic in forensic situations. However, there were no noticeable increases in the cytokine levels (data not shown).

\section{Discussion}

The cytokines analyzed in the present study are all involved in the pathways of inflammatory response and tissue injury (Kelder et al. 2012; Romagnani et al. 2006; Kutmon et al. 2016), and the expression of most of cytokine was significantly upregulated after the skeletal muscle injury.

As early and acute responders, protein expression of IL-6 and CXCL1 in injured muscle tissues significantly increased during the first 6 hours after injury, followed by a
Table 2. Mean concentration of each cytokine in serum at each time point ( $\mathrm{pg} / \mathrm{mL}, \mathrm{n}=8$ for each group).

\begin{tabular}{crrrrr}
\hline & \multicolumn{1}{c}{$0 \mathrm{~h}$} & \multicolumn{1}{c}{$6 \mathrm{~h}$} & \multicolumn{1}{c}{$12 \mathrm{~h}$} & \multicolumn{1}{c}{$24 \mathrm{~h}$} & \multicolumn{1}{c}{$48 \mathrm{~h}$} \\
\hline IL-1 $\beta$ & 22.3 & 17.8 & 16.0 & 17.8 & 250.5 \\
IL-6 & 250.9 & 229.4 & 167.2 & 237.6 & 278.3 \\
IL-7 & 5.9 & 4.0 & 5.5 & 3.8 & 83.5 \\
CCL2 & 111.8 & 137.2 & 97.9 & 77.3 & 457.7 \\
CCL3 & 308.0 & 239.3 & 258.9 & 195.3 & 507.1 \\
CCL4 & 234.0 & 183.9 & 211.6 & 175.0 & 388.8 \\
CXCL1 & 15.0 & 569.8 & 188.1 & 248.1 & 438.1 \\
CXCL2 & 319.5 & 325.5 & 261.8 & 241.4 & 488.3 \\
CXCL10 & 173.9 & 164.9 & 180.8 & 198.0 & 299.4 \\
\hline
\end{tabular}

Table 3. Summary of the expression profile of each cytokine mRNA in muscle tissue after injury.

IL-6*, CXCL1, CXCL2:

Significantly increased at 6 hours after injury, followed by a significant decrease at 12 hours, but maintained at the elevated levels during 48 hours.

CCL2, CCL3, CXCL10:

Significantly increased at 6 hours after injury and maintained at elevated levels during 48 hours.

IL-1 $\beta^{*}$, CCL4*:

Significantly increased at 6 hours after injury and maintained at the elevated levels during 48 hours, but with a significant decrease at 48 hours.

IL-7*: Significantly increased at 12 hours and continuously increased during 48 hours.

*Reported in the previous study (Gaballah et al. 2016).

rapid decline. IL-6, as a myokine, plays an important role in initiating muscle regeneration and growth by stimulating myoblasts and satellite cell proliferation, and myotube formation that promotes myogenesis (Munõz-Cánoves et al. 2013). On the other hand, the release of CXCL1 from stimulated endothelial cells (Wen et al. 1989) may explain its rapid and high release immediately after injury infliction. Also, it was noted that CXCL1 can be released from activated or mechanically stimulated muscles, which can initiate specific immune responses in injured muscle with subsequent muscle regeneration (Tidball and Villalta 2010).

The results of protein immunoassay of muscle samples showed a significant increase of IL- $1 \beta$ concentrations throughout the post-injury periods. IL- $1 \beta$ plays various roles in the repair process of injured muscle (Authier et al. 1999), and its mRNA expression in an incised skin wound model showed a peak level of expression at 3 days after injury (Sato and Ohshima 2000). Therefore, IL-1 $\beta$ could be a late phase marker for muscle wound aging. On the other hand, IL-7 is considered as a myokine that increases myogenesis and migration of satellite cells, which would help in the healing of injured muscle (Aoi and Sakuma 2013). IL-7 in the muscle tissue showed the unique expression profile; namely, its tissue levels remained below the detection limit during 24 hours after injury, followed by significant expres- 

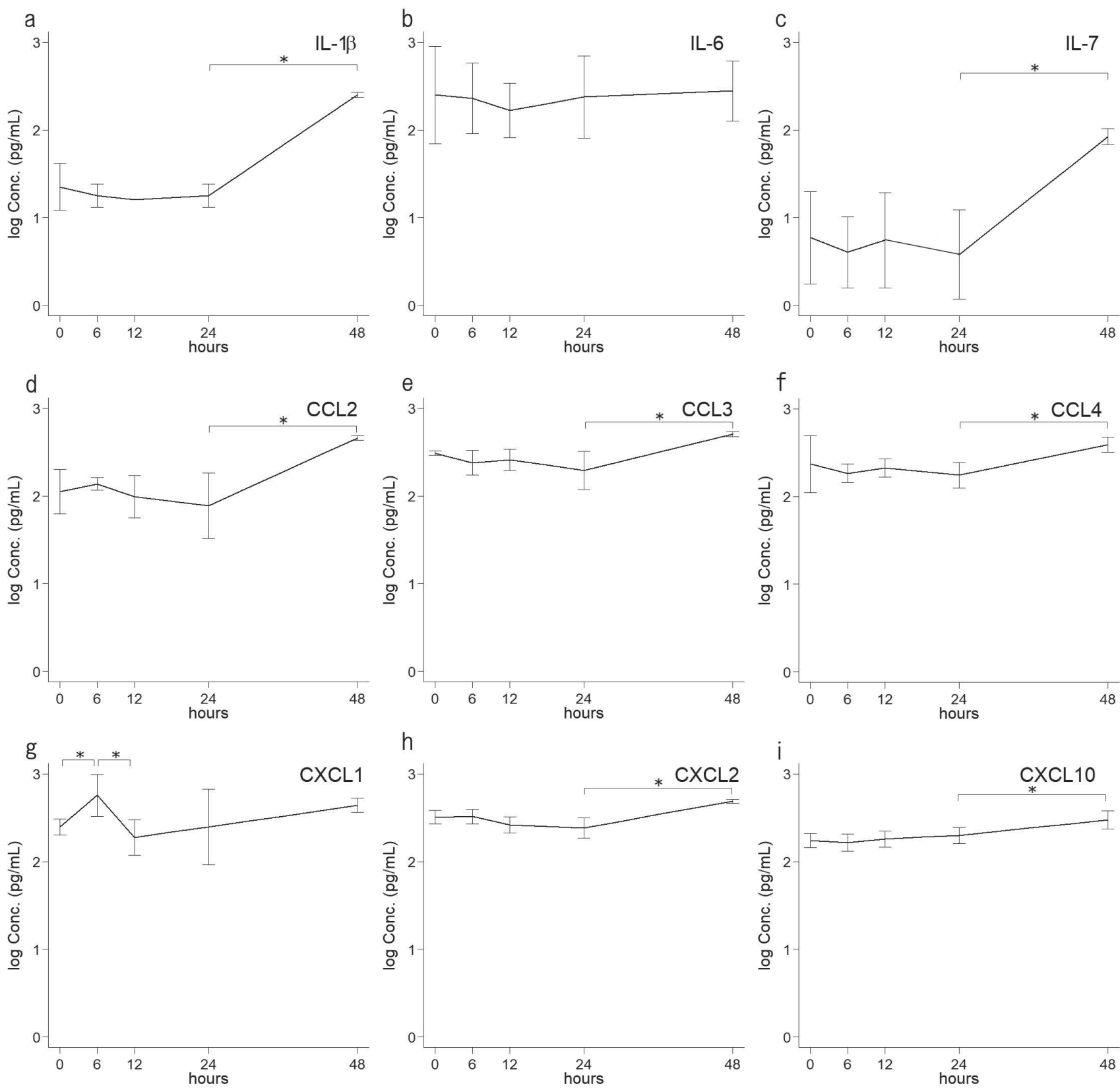

Fig. 2. Semi-log graphs of serum levels of the cytokines.

Serum levels of 7 cytokines, namely IL-1 $\beta$ (a), IL-7 (c), CCL2 (d), CCL3 (e), CCL4 (f), CXCL2 (h), and CXCL10 (i), showed a late increase from 24 hours to 48 hours after injury. Levels of IL-6 (b) remained unchanged during 48 hours after injury. CXCL1 (g) showed an increase in concentrations at 6 hours, and then decreased to the basal levels at 12 hours after injury. $* P<0.05$.

sion at 48 hours (see Fig. 1c). Consistently in part with the delayed increase in IL-7 protein levels, the expression level of IL-7 mRNA was significantly increased at 12 hours and further increased at 48 hours (Gaballah et al. 2016) (Table 3). These results indicate that IL-7 is a good late-phase marker for wound aging of the muscle. Another later responder was CXCL10 (Fig. 1i), which has a regenerative and angiogenic function during muscle healing (Shireman 2007).

CCL2, CCL3 and CCL4 trigger potent proliferative effects on myoblasts which significantly affect the healing process after infliction of skeletal muscle injury (Yahiaoui et al. 2008). In case of CCL4, its protein expression was significantly increased only at 48 hours after injury. The increase in protein expression in the later phase was also detected in CCL2. By contrast, CCL3 protein levels in muscle tissues were increased to a peak at 12 hours. Thus, CCL 2 and CCL 4 could be characterized as late phase markers of muscle injury.

Serum levels of most cytokines, except for CXCL1, 
were relatively stable during 24 hours after injury, followed by a mild but significant increase. Importantly, serum CXCL1 levels were increase at 6 hours after injury and rapidly decreased to the basal levels at 12 hours (Fig. 2g). These changes also support that CXCL1 is a good earlyphase marker for estimating wound aging.

Various studies have revealed that the release of proinflammatory cytokines into systemic circulation is usually inhibited, and many inhibitory mechanisms have been suggested, including counter release of inhibitory cytokines and cytokine receptors to limit the systemic inflammatory response (Pedersen and Hoffman-Goetz 2000). Therefore, the local muscular environment should not directly affect the levels of muscular markers in systemic circulation. In addition, expression of the cytokine mRNA was barely elevated in the biceps femoris muscle of contralateral side (the right side) of the injured mice (data not shown). Hence, the systemic environment should have little effect on the local dynamics of the injury-related cytokines. Thus, these cytokines would be available as local markers for pathological and clinical evaluation of injuries.

The data obtained in the present study might be applicable to the blunt force injuries that are much more common in actual cases than sharp force ones. However, in our incised injury model, an earlier increase in IL- 6 and IL-1 $\beta$ mRNA expression was observed compared with that in the contusion model (Perl et al. 2003; Gaballah et al. 2016), suggesting that expression of the cytokines would be dependent on the type of injury. Although quantification and standardization of the forces or damage is somewhat complicated in the case of blunt injuries, further investigation is needed to fully understand the dynamics of cytokines after muscle injuries. Also, in practical forensic settings, factors related to local or systemic infection, which were controlled in the present and most reported studies on wound aging performed in sterilized conditions, must be taken into account, as well as the subject's general status, to evaluate the dynamics of cytokines following inflammation (van der Laan et al. 2001; Cecchi 2010).

The present study highlights the expression profiles of cytokines using protein immunoassay for detection of new reliable markers for forensic wound age estimation in incised skeletal muscle wounds. Most of the cytokines investigated in this study showed rapid increase in the protein levels, and their elevated levels were maintained during 48 hours after injury. In particular, CXCL1 and IL-7 would be reliable indicators for wound aging in the early and late phases, respectively.

\section{Acknowledgments}

The authors thank Mr. Miyoshi, S. at Merck Ltd. for his technical guidance in bead-based immunoassay.

\section{Conflict of Interest}

The authors declare no conflict of interest.

\section{References}

Aoi, W. \& Sakuma, K. (2013) Skeletal muscle: novel and intriguing characteristics as a secretory organ. BioDiscovery, 7, e8942.

Authier, F.J., Chazaud, B., Plonquet, A., Eliezer-Vanerot, M.C., Poron, F., Belec, L., Barlovatz-Meimon, G. \& Gherardi, R.K. (1999) Differential expression of the IL-1 system components during in vitro myogenesis: implication of IL-1beta in induction of myogenic cell apoptosis. Cell Death Differ., 6, 10121021.

Cecchi, R. (2010) Estimating wound age: looking into the future. Int. J. Legal Med., 124, 523-536.

Gaballah, M., Fukuta, M., Maeno, Y., Seko-Nakamura, Y., MonmaOhtaki, J., Shibata, Y., Kato, H., Aoki, Y. \& Takamiya, M. (2016) Simultaneous time course analysis of multiple markers based on DNA microarray in incised wound in skeletal muscle for wound aging. Forensic Sci. Int., 266, 357-368.

Grellner, W. \& Madea, B. (2007) Demands on scientific studies: vitality of wounds and wound age estimation. Forensic Sci. Int., 165, 150-154.

Kelder, T., van Iersel, M.P., Hanspers, K., Kutmon, M., Conklin, B.R., Evelo, C.T. \& Pico, A.R. (2012) WikiPathways: building research communities on biological pathways. Nucleic Acids Res., 40, D1301-1307.

Kutmon, M., Riutta, A., Nunes, N., Hanspers, K., Willighagen, E.L., Bohler, A., Melius, J., Waagmeester, A., Sinha, S.R., Miller, R., Coort, S.L., Cirillo, E., Smeets, B., Evelo, C.T. \& Pico, A.R. (2016) WikiPathways: capturing the full diversity of pathway knowledge. Nucleic Acids Res., 44, D488-494.

Madea, B. \& Saukko, P. (2010) Molecular pathology in forensic medicine. Preface. Forensic Sci. Int., 203, 1-2.

Maeda, H., Zhu, B.L., Ishikawa, T. \& Michiue, T. (2010) Forensic molecular pathology of violent deaths. Forensic Sci. Int., 203, 83-92.

Munõz-Cánoves, P., Scheele, C., Pedersen, B.K. \& Serrano, A.L. (2013) Interleukin-6 myokine signaling in skeletal muscle: a double-edged sword? FEBS J., 280, 4131-4148.

Pedersen, B.K. \& Hoffman-Goetz, L. (2000) Exercise and the immune system: regulation, integration, and adaptation. Physiol. Rev., 80, 1055-1081.

Perl, M., Gebhard, F., Knoferl, M.W., Bachem, M., Gross, H.J., Kinzl, L. \& Strecker, W. (2003) The pattern of preformed cytokines in tissues frequently affected by blunt trauma. Shock, 19, 299-304.

Romagnani, P., Lasagni, L. \& Romagnani, S. (2006) Chemokine receptors in tissue cells and angiogenesis. In Chemokine Biology - Basic Research and Clinical Application. Volume I: Immunobiology of Chemokines, edited by Moser, B., Letts, G.L. \& Neote, K., Birkhäuser, Basel, Switzerland, pp. 183203.

Sato, Y. \& Ohshima, T. (2000) The expression of mRNA of proinflammatory cytokines during skin wound healing in mice: A preliminary study for forensic wound age estimation (II). Int. J. Legal Med., 113, 140-145.

Schwanhäusser, B., Busse, D., Li, N., Dittmar, G., Schuchhardt, J., Wolf, J., Chen, W. \& Selbach, M. (2011) Global quantification of mammalian gene expression control. Nature, 473, 337-342.

Shireman, P.K. (2007) The chemokine system in arteriogenesis and hind limb ischemia. J. Vasc. Surg., 45, A48-56.

Takamiya, M., Biwasaka, H., Saigusa, K., Nakayashiki, N. \& Aoki, Y. (2009) Wound age estimation by simultaneous detection of 9 cytokines in human dermal wounds with a multiplex beadbased immunoassay: an estimative method using outsourced examinations. Legal Med., 11, 186-190.

Takamiya, M., Fujita, S., Saigusa, K. \& Aoki, Y. (2007) Simultaneous detection of eight cytokines in human dermal wounds 
with a multiplex bead-based immunoassay for wound age estimation. Int. J. Legal Med., 122, 143-148.

Tian, Z.L., Jiang, S.K., Zhang, M., Wang, M., Li, J.Y., Zhao, R., Wang, L.L., Li, S.S., Liu, M., Zhang, M.Z. \& Guan, D.W. (2016) Detection of satellite cells during skeletal muscle wound healing in rats: time-dependent expressions of Pax7 and MyoD in relation to wound age. Int. J. Legal Med., 130, 163-172.

Tidball, J.G. \& Villalta, S.A. (2010) Regulatory interactions between muscle and the immune system during muscle regeneration. Am. J. Physiol. Regul. Integr. Comp. Physiol., 298, R1173-1187.

van der Laan, N., de Leij, L.F.M.H. \& ten Duis, H.J. (2001)
Immunohistopathological appearance of three different types of injury in human skin. Inflamm. Res., 50, 350-356.

Wen, D.Z., Rowland, A. \& Derynck, R. (1989) Expression and secretion of gro/MGSA by stimulated human endothelial cells. EMBO J., 8, 1761-1766.

Yahiaoui, L., Gvozdic, D., Danialou, G., Mack, M. \& Petrof, B.J. (2008) CC family chemokines directly regulate myoblast responses to skeletal muscle injury. J. Physiol., 586, 39914004.

Yu, T., Li, Z., Zhao, R., Zhang, Y., Zhang, Z. \& Guan, D. (2016) Time-dependent expression of MMP-2 and TIMP-2 after rats skeletal muscle contusion and their application to determine wound age. J. Forensic Sci., 61, 527-533. 